\title{
Metal-free nucleophilic trifluoromethylselenolation via an iodide-mediated umpolung reactivity of trifluoromethylselenotoluenesulfonate
}

\author{
Kevin Grollier ${ }^{\ddagger 1}$, Alexis Taponard ${ }^{\ddagger 1}$, Arnaud De Zordo-Banliat ${ }^{2}$, Emmanuel Magnier ${ }^{2}$ \\ and Thierry Billard ${ }^{*} 1,3$
}

Open Access

\author{
Full Research Paper \\ Address: \\ ${ }^{1}$ Institute of Chemistry and Biochemistry (ICBMS-UMR CNRS 5246), \\ Univ Lyon, Université Lyon 1, CNRS, CPE, INSA, 43 Bd du 11 \\ novembre 1918, 69622 Villeurbanne, France, ${ }^{2}$ Université \\ Paris-Saclay, UVSQ, CNRS, UMR 8180, Institut Lavoisier de \\ Versailles, 78035 Versailles Cedex, France and ${ }^{3}$ CERMEP-In vivo \\ imaging, Groupement Hospitalier Est, 59 Bd Pinel, 69677 Lyon, \\ France \\ Email: \\ Thierry Billard* - Thierry.billard@univ-lyon1.fr \\ * Corresponding author $\ddagger$ Equal contributors \\ Keywords: \\ fluorine; nucleophilic substitution; perfluoroalkylselenolation; \\ selenium; trifluoromethylselenolation
}

Beilstein J. Org. Chem. 2020, 16, 3032-3037.

https://doi.org/10.3762/bjoc.16.252

Received: 23 October 2020

Accepted: 02 December 2020

Published: 10 December 2020

This article is part of the thematic issue "Organo-fluorine chemistry V".

Guest Editor: D. O'Hagan

(c) 2020 Grollier et al.; licensee Beilstein-Institut.

License and terms: see end of document.

\begin{abstract}
We report herein a practical method to generate $\mathrm{CF}_{3} \mathrm{Se}^{-}$(and $\mathrm{R}_{\mathrm{F}} \mathrm{Se}^{-}$) anions from shelf-stable reagents under iodide activation. Metal-free nucleophilic trifluoromethylselenolations have been then performed with this in situ-generated anion. Perfluoroalkylselenolations have also been described.
\end{abstract}

\section{Introduction}

Because of the peculiar properties of the fluorine atom, fluorinated compounds gained a growing interest over the last decades and found applications in a large panel of fields from materials to life sciences [1-15]. Fluorinated motifs bring to molecules specific and often unique electronic and physicochemical characteristics. In order to design new substrates with targeted properties, a modulation of the properties of the introduced substituents became fundamental. In this context, the development of innovative fluorinated groups recently emerged, in particular by combining heteroatoms, such as chalcogens, and fluorinated moieties [16].

Despite, the negative reputation of selenium due to its toxicity at high doses, it is an essential trace element for human physiology and biochemistry [17-20]. Furthermore, selenolated compounds found valuable applications in materials [21-23], life sciences [19,20,24-29], and drug design [30-33]. Consequently, the merging of fluorinated moieties, such as $\mathrm{CF}_{3}$ with selenium 
could constitute an interesting motif in the design of new molecules, in particular in medicinal chemistry or agrochemistry. Even if, to date, there are no $\mathrm{CF}_{3} \mathrm{Se}$-containing pharmaceuticals registered [15], a recent work has demonstrated the promising development of trifluoromethylselenolated nonsteroidal antiinflammatory drugs as potential anticancer drugs [34].

Over the last years, trifluoromethylselenolation reactions have gained a rising infatuation but, despite this recent interest, methods to introduce the $\mathrm{CF}_{3} \mathrm{Se}$ group into organic substrates remain limited [35,36].

One of the simplest ways to achieve trifluoromethylselenolated compounds is the direct nucleophilic substitution of suitable leaving groups to form the $\mathrm{CF}_{3} \mathrm{Se}-\mathrm{C}\left(\mathrm{sp}^{3}\right)$ bond. This chemistry is the prerogative of the $\mathrm{CF}_{3} \mathrm{Se}^{-}$anion (Scheme 1) [37-40] However, the formation of this selenium species requires the tedious use of red elemental selenium [41] and also suffers from stability issues. To circumvent these drawbacks, a copper com-

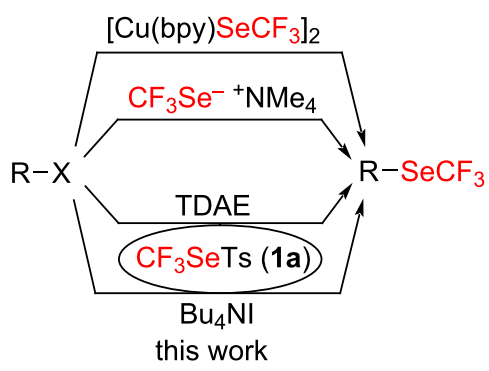

Scheme 1: State of the art concerning the direct nucleophilic trifluoromethylselenolation. plex has been developed, but in this case the use of a stoichiometric amount of the metal is required [37-39].

Only a few years ago, trifluoromethylselenotoluenesulfonate (1a) has been developed as an efficient reagent to perform electrophilic or radical trifluoromethylselenolations [42-47]. Very recently, we demonstrated that under reductive conditions, such compounds succeeded to perform nucleophilic substitutions [48]. In this reaction, the $\mathrm{CF}_{3} \mathrm{Se}^{-}$anion was in situ generated by reduction through a double electron transfer of 1a with TDAE (tetrakis(dimethylamino)ethylene). Even though this umpolung strategy is efficient, the use of the sensitive TDAE, a strong reducing agent, could constitute a drawback for some applications. Consequently, we decided to develop a new umpolung method in non-reductive conditions.

\section{Results and Discussion}

A few years ago, we have demonstrated that trifluoromethanesulfenamides, electrophilic trifluoromethylthiolation reagents, could also perform nucleophilic trifluoromethylthiolations through the transient formation of a $\mathrm{CF}_{3} \mathrm{SI}$ species which presented an inverted polarity $[49,50]$. Based on a similar approach, we hypothesized that the $\mathrm{CF}_{3} \mathrm{SeI}$ species could also possess the $\mathrm{CF}_{3} \mathrm{Se}^{\delta-}-\mathrm{I}^{\delta+}$ inverted polarity. Thus, based on the previously developed conditions, reagent 1a was reacted with benzyl bromide (2a) in the presence of tetrabutylammonium iodide (TBAI) in acetone at $40{ }^{\circ} \mathrm{C}$ (Table 1 , entry 1 ).

The observed result was moderate (Table 1, entry 1). Other solvents, which led also to satisfactory yields in the "sulfur series" were then tested. Acetonitrile did not improve the yield, howev-

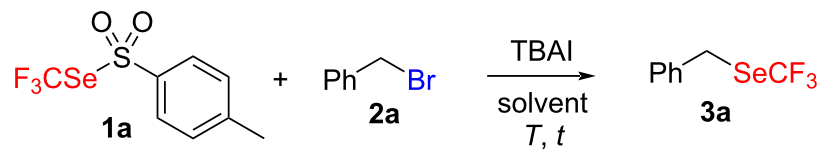

\begin{tabular}{|c|c|c|c|c|c|c|c|}
\hline entry & $\begin{array}{l}\text { 1a } \\
\text { (equiv) }\end{array}$ & $\begin{array}{l}\text { TBAI } \\
\text { (equiv) }\end{array}$ & $\begin{array}{l}\mathbf{2 a} \\
\text { (equiv) }\end{array}$ & solvent & $\begin{array}{l}T \\
\left({ }^{\circ} \mathrm{C}\right)\end{array}$ & $\begin{array}{l}t \\
\text { (h) }\end{array}$ & $\begin{array}{l}3 a \\
(\%)^{a}\end{array}$ \\
\hline 1 & 1 & 2 & 1 & acetone & 40 & 15 & 52 \\
\hline 2 & 1 & 2 & 1 & $\mathrm{CH}_{3} \mathrm{CN}$ & 40 & 15 & 54 \\
\hline 3 & 1 & 2 & 1 & THF & 40 & 15 & 61 \\
\hline 4 & 1 & 2 & 1 & THF & 40 & 4 & 62 \\
\hline 5 & 1 & 2 & 1 & $\mathrm{THF}$ & 50 & 4 & 59 \\
\hline 6 & 1 & 2 & 1 & THF & 60 & 4 & 54 \\
\hline 7 & 1 & 2 & 1 & $\mathrm{THF}$ & 25 & 4 & 47 \\
\hline 8 & 1.5 & 3 & 1 & THF & 40 & 4 & 55 \\
\hline 9 & 1 & 2 & 2 & THF & 40 & 4 & 89 \\
\hline
\end{tabular}

aYields determined by ${ }^{19} \mathrm{~F}$ NMR spectroscopy with $\mathrm{PhOCF}_{3}$ as an internal standard. 
er, a better one was obtained in THF (Table 1, entries 2 and 3). Interestingly, a shorter reaction time ( $4 \mathrm{~h}$ instead of $15 \mathrm{~h}$ ) provided similar results (Table 1, entries 3 and 4). At higher temperatures, the results were not improved and even a slight decrease of the yield was observed, possibly due to an increased degradation of $\mathrm{CF}_{3} \mathrm{SeI}$ or $\mathrm{CF}_{3} \mathrm{Se}^{-}$(Table 1, entries 5 and 6). A lower temperature also decreased the yield (Table 1, entry 7). With an excess of reagents 1a and TBAI, leading to an excess of the $\mathrm{CF}_{3} \mathrm{Se}^{-}$species, no significant improvement was observed (Table 1, entry 8). On contrary, the use of 2 equivalents of the electrophile 2a, to ameliorate the $\mathrm{CF}_{3} \mathrm{Se}^{-}$anion trapping, had a significant effect and gave a very good yield of the product (Table 1, entry 9). With the optimal conditions in hand, the reaction was exemplified with various other electrophiles (Scheme 2).

The reaction gave generally good results with reactive electrophiles such as benzylic, allylic or propargylic ones (3a-k). Noteworthy, in the reaction with 2-(bromomethyl)pyridine (2g) only 1 equivalent was required, maybe due to a higher reactivity. Furthermore, the reaction seems to be very sensitive to steric hindrance as illustrated by the low yield obtained for $\mathbf{3 b}$. In contrast, in the aliphatic series, only low yields were observed (3m,n) except for the activated $\alpha$-bromo acetophenone (31). This led us to suppose that $\mathrm{CF}_{3} \mathrm{Se}^{-}$might be a poor nucleophile, which is confirmed by the medium yield observed with the propargylic substrate $\mathbf{3 k}$, where the chloride starting material was used instead of the bromide as for the other compounds. Noteworthy, because of the volatility of the obtained products, the isolated yields were sometimes significantly below the NMR yields.

Higher fluorinated homologs of 1a were also synthesized. Consequently, an extension of this method was considered with pentafluoroethylated and tridecafluorohexylated reagents $\mathbf{1 b}$ and 1c. Good yields were obtained, in particular for $\mathbf{5 a}$ which constitutes, to the best of our knowledge, the first example of a direct nucleophilic tridecafluorohexylselenolation.

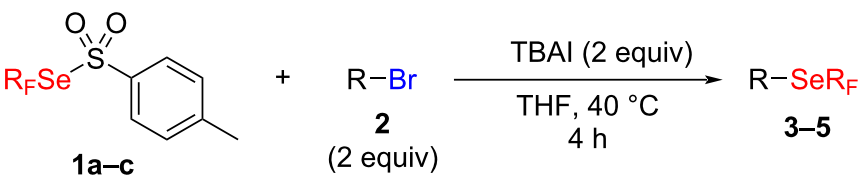

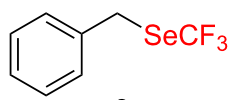
$89 \%(75 \%)$<smiles>O=[N+]([O-])c1ccc(C[Se]OC(F)(F)F)cc1</smiles>

$87 \%(65 \%)$<smiles>FC(F)(F)[Se]CC=Cc1ccccc1</smiles>
$91 \%(80 \%)$<smiles>O=C(C[SeH](F)(F)F)c1ccccc1</smiles>

$95 \%(68 \%)$<smiles>CC(c1ccccc1)C(F)(F)F</smiles>
$12 \%$

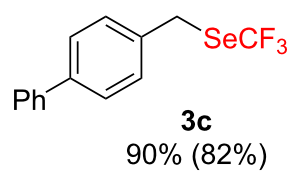<smiles>FC(F)(F)[Se]Cc1ccccn1</smiles>

$3 \mathrm{~g}$ $94 \%(75 \%)^{\mathrm{a}}$<smiles>Fc1ccc(C[Se]C(F)(F)F)cc1</smiles>
$83 \%(52 \%)$<smiles>O=[N+]([O-])c1ccc(C[Se]C(F)(F)F)o1</smiles>

3h 95\% (60\%) $74 \%(69 \%)$<smiles>CC(C)=CCC/C(C)=C/C[Se]C(F)(F)F</smiles>
3j $83 \%(77 \%)$<smiles>FC(F)(F)[Se]CC#Cc1ccccc1</smiles><smiles>FC(F)(F)O[Si]CCc1ccccc1</smiles>

$20 \%$<smiles>FC(F)(F)C(F)(F)[Se]Cc1ccccn1</smiles>

$(65 \%)^{\mathrm{a}}$<smiles></smiles> 
From a mechanistic point of view, a pathway inspired by the reaction described with trifluoromethanesulfenamides was postulated (Scheme 3) [49].

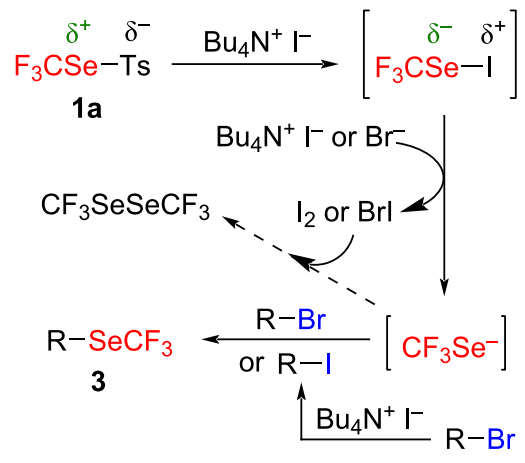

Scheme 3: Mechanism proposal.

The first equivalent of iodide (from TBAI) reacts with the reagent $1 \mathrm{a}$ to produce the transient species $\mathrm{CF}_{3} \mathrm{SeI}$ with an inverted polarity on the selenium atom. This compound then undergoes the attack of the second equivalent of iodide to generate the $\mathrm{CF}_{3} \mathrm{Se}^{-}$anion with releasing of $\mathrm{I}_{2}$. Finally, the nucleophilic $\mathrm{CF}_{3} \mathrm{Se}^{-}$can substitute the leaving group onto the electrophilic substrate 2. However, because of the release of $\mathrm{I}_{2}$, as side reaction the oxidation of the $\mathrm{CF}_{3} \mathrm{Se}^{-}$anion can be also envisaged. This was confirmed by the formation of $25-30 \%$ of $\mathrm{CF}_{3} \mathrm{SeSeCF}_{3}$ when 1 equivalent of $\mathbf{2 a}$ was used (Table 1 , entries 3 and 4). Consequently, the nucleophilic substitution is in competition with this relatively fast oxidation. By adding an excess of the electrophile $\mathbf{2}$, the substitution is favored detrimentally to the oxidation. Nevertheless, with weaker or hindered electrophiles, the oxidation reaction is favored compared to the slower substitution. This is adequate with the observed results. Noteworthy, the supposed formation of $I_{2}$ was strengthened by the appearance of a red-brown color of the reaction media which faded after the addition of sodium thiosulfate. As demonstrated in the sulfur series [49], the in situ formation of an alkyl iodide from 2, through a Finkelstein reaction, can be also envisaged. This would not impact the reaction pathway since the released bromide can also activate the $\mathrm{CF}_{3} \mathrm{SeI}$ species to provide the expected $\mathrm{CF}_{3} \mathrm{Se}^{-}$anion.

\section{Conclusion}

To conclude, trifluoromethylselenotoluenesulfonate confirmed to be a versatile reagent able to perform electrophilic, radical or nucleophilic reactions depending on the conditions. The iodidemediated, metal-free method is complementary to the previous one using TDAE. Thus, the umpolung reactivity of trifluoromethylselenotoluenesulfonate can be performed under reduc- tive or oxidative conditions. Furthermore, this method was extended to higher fluorinated homologs allowing the first nucleophilic tridecafluorohexylselenolation.

\section{Experimental}

Typical procedure: In a $10 \mathrm{~mL}$ flame-dried flask tube equipped with a magnetic stirring bar was added 1a-c $(0.2 \mathrm{mmol}$, 1 equiv) followed by $0.4 \mathrm{~mL}$ of dry THF. Then, compound 2a-n ( 0.4 mmol, 2 equiv) was added followed by TBAI ( $0.4 \mathrm{mmol}, 2$ equiv). The tube is then sealed and the reaction mixture stirred at $40{ }^{\circ} \mathrm{C}$ for $4 \mathrm{~h}$. The conversion was checked by ${ }^{19}$ F NMR spectroscopy with $\mathrm{PhOCF}_{3}$ as internal standard. After completion, the reaction mixture was partitioned between $\mathrm{Et}_{2} \mathrm{O}$ or pentane and water. The aqueous layer was extracted with $\mathrm{Et}_{2} \mathrm{O}$ and pentane and the combined organic layers were dried over $\mathrm{MgSO}_{4}$, filtered and concentrated to dryness. The crude residue was purified by chromatography to afford the desired products $\mathbf{3}, \mathbf{4}$, or $\mathbf{5}$.

\section{Supporting Information}

\section{Supporting Information File 1}

Additional experimental and analytical data.

[https://www.beilstein-journals.org/bjoc/content/

supplementary/1860-5397-16-252-S1.pdf]

\section{Funding}

This work was supported by a grant from the French National Research Agency (ANR 18-CE07-0039-01). The authors are grateful to the CNRS and the French Ministry of Research for financial support. The French Fluorine Network is also acknowledged for its support.

\section{ORCID ${ }^{\circledR}$ iDs}

Kevin Grollier - https://orcid.org/0000-0003-0850-8653 Alexis Taponard - https://orcid.org/0000-0001-8008-2293 Emmanuel Magnier - https://orcid.org/0000-0003-3392-3971 Thierry Billard - https://orcid.org/0000-0002-2937-9523

\section{References}

1. Smart, B. E. J. Fluorine Chem. 2001, 109, 3-11. doi:10.1016/s0022-1139(01)00375-x

2. Kirsch, P. Modern Fluoroorganic Chemistry; Wiley-VCH: Weinheim, Germany, 2013. doi:10.1002/9783527651351

3. Zhou, Y.; Wang, J.; Gu, Z.; Wang, S.; Zhu, W.; Aceña, J. L.; Soloshonok, V. A.; Izawa, K.; Liu, H. Chem. Rev. 2016, 116, 422-518. doi:10.1021/acs.chemrev.5b00392

4. Meanwell, N. A. J. Med. Chem. 2018, 61, 5822-5880. doi:10.1021/acs.jmedchem.7b01788 
5. Mei, H.; Han, J.; Fustero, S.; Medio-Simon, M.; Sedgwick, D. M.; Santi, C.; Ruzziconi, R.; Soloshonok, V. A. Chem. - Eur. J. 2019, 25, 11797-11819. doi:10.1002/chem.201901840

6. Han, J.; Remete, A. M.; Dobson, L. S.; Kiss, L.; Izawa, K.; Moriwaki, H.; Soloshonok, V. A.; O'Hagan, D. J. Fluorine Chem. 2020, 239, 109639. doi:10.1016/j.jfluchem.2020.109639

7. Cheng, M.; Guo, C.; Gross, M. L. Angew. Chem., Int. Ed. 2020, 59, 5880-5889. doi:10.1002/anie.201907662

8. Johnson, B. M.; Shu, Y.-Z.; Zhuo, X.; Meanwell, N. A. J. Med. Chem. 2020, 63, 6315-6386. doi:10.1021/acs.jmedchem.9b01877

9. Jeschke, P. Pest Manage. Sci. 2010, 66, 10-27. doi:10.1002/ps.1829

10. Ogawa, Y.; Tokunaga, E.; Kobayashi, O.; Hirai, K.; Shibata, N. iScience 2020, 23, 101467. doi:10.1016/j.isci.2020.101467

11. Fujiwara, T.; O'Hagan, D. J. Fluorine Chem. 2014, 167, 16-29. doi:10.1016/j.jluchem.2014.06.014

12. Pagliaro, M.; Ciriminna, R. J. Mater. Chem. 2005, 15, 4981-4991. doi:10.1039/b507583c

13. Berger, R.; Resnati, G.; Metrangolo, P.; Weber, E.; Hulliger, J. Chem. Soc. Rev. 2011, 40, 3496-3508. doi:10.1039/c0cs00221f

14. Chopra, D.; Row, T. N. G. CrystEngComm 2011, 13, 2175-2186. doi:10.1039/c0ce00538j

15. Inoue, M.; Sumii, Y.; Shibata, N. ACS Omega 2020, 5, 10633-10640. doi:10.1021/acsomega.0c00830

16. Cahard, D.; Ma, J.-A., Eds. Emerging Fluorinated Motifs: Synthesis, Properties and Applications; Wiley-VCH: Weinheim, Germany, 2020. doi:10.1002/9783527824342

17. EFSA Panel on Dietetic Products, Nutrition and Allergies. EFSA J. 2014, 12, 3846. doi:10.2903/j.efsa.2014.3846

18. European Food Safety Authority (EFSA). EFSA Supporting Publ. 2017, 14, e15121E. doi:10.2903/sp.efsa.2017.e15121

19. Rayman, M. P. Lancet 2000, 356, 233-241. doi:10.1016/s0140-6736(00)02490-9

20. Mousa, R.; Notis Dardashti, R.; Metanis, N. Angew. Chem., Int. Ed. 2017, 56, 15818-15827. doi:10.1002/anie.201706876

21. Romashov, L. V.; Ananikov, V. P. Chem. - Eur. J. 2013, 19, 17640-17660. doi:10.1002/chem.201302115

22. Guo, W.; Fu, Y. Chem. - Eur. J. 2020, 26, 13322-13331. doi:10.1002/chem.202000878

23. Li, Q.; Zhang, Y.; Chen, Z.; Pan, X.; Zhang, Z.; Zhu, J.; Zhu, X. Org. Chem. Front. 2020, 7, 2815-2841. doi:10.1039/d0qo00640h

24. Mugesh, G.; du Mont, W.-W.; Sies, H. Chem. Rev. 2001, 101, 2125-2180. doi:10.1021/cr000426w

25. Rocha, J. B. T.; Piccoli, B. C.; Oliveira, C. S. ARKIVOC 2017, No. ii, 457-491. doi:10.24820/ark.5550190.p009.784

26. Short, S. P.; Pilat, J. M.; Williams, C. S. Free Radical Biol. Med. 2018, 127, 26-35. doi:10.1016/j.freeradbiomed.2018.05.066

27. Solovyev, N.; Drobyshev, E.; Bjørklund, G.; Dubrovskii, Y.; Lysiuk, R.; Rayman, M. P. Free Radical Biol. Med. 2018, 127, 124-133. doi:10.1016/j.freeradbiomed.2018.02.030

28. Antoniadou, I.; Kouskou, M.; Arsiwala, T.; Singh, N.; Vasudevan, S. R.; Fowler, T.; Cadirci, E.; Churchill, G. C.; Sharp, T. Br. J. Pharmacol. 2018, 175, 2599-2610. doi:10.1111/bph.14179

29. Jain, V. K.; Priyadarsini, K. I., Eds. Organoselenium Compounds in Biology and Medicine: Synthesis, Biological and Therapeutic Treatments; Royal Society of Chemistry: Cambridge. U.K., 2018. doi:10.1039/9781788011907

30. Singh, N.; Halliday, A. C.; Thomas, J. M.; Kuznetsova, O. V.; Baldwin, R.; Woon, E. C. Y.; Aley, P. K.; Antoniadou, I.; Sharp, T.; Vasudevan, S. R.; Churchill, G. C. Nat. Commun. 2013, 4, 1332. doi:10.1038/ncomms2320
31. Thangamani, S.; Younis, W.; Seleem, M. N. Sci. Rep. 2015, 5, 11596. doi:10.1038/srep11596

32. Gandin, V.; Khalkar, P.; Braude, J.; Fernandes, A. P.

Free Radical Biol. Med. 2018, 127, 80-97. doi:10.1016/j.freeradbiomed.2018.05.001

33. Alcolea, V.; Pérez-Silanes, S. Eur. J. Med. Chem. 2020, 206, 112673. doi:10.1016/j.ejmech.2020.112673

34. He, X.; Zhong, M.; Li, S.; Li, X.; Li, Y.; Li, Z.; Gao, Y.; Ding, F.; Wen, D.; Lei, Y.; Zhang, Y. Eur. J. Med. Chem. 2020, 208, 112864. doi:10.1016/j.ejmech.2020.112864

35. Tlili, A.; Ismalaj, E.; Glenadel, Q.; Ghiazza, C.; Billard, T. Chem. - Eur. J. 2018, 24, 3659-3670. doi:10.1002/chem.201704637

36. Billard, T.; Toulgoat, F. When Fluorine Meets Selenium. In Emerging Fluorinated Motifs: Synthesis, Properties and Applications; Cahard, D.; Ma, J.-A., Eds.; Wiley-VCH: Weinheim, Germany, 2020; pp 691-721. doi:10.1002/9783527824342.ch23

37. Chen, C.; Ouyang, L.; Lin, Q.; Liu, Y.; Hou, C.; Yuan, Y.; Weng, Z. Chem. - Eur. J. 2014, 20, 657-661. doi:10.1002/chem.201303934

38. Rong, M.; Huang, R.; You, Y.; Weng, Z. Tetrahedron 2014, 70 , 8872-8878. doi:10.1016/j.tet.2014.09.091

39. Yang, Y.; Lin, X.; Zheng, Z.; Lin, G.; Zhang, Y.; You, Y.; Weng, Z. J. Fluorine Chem. 2017, 204, 1-5. doi:10.1016/j.jfluchem.2017.10.001

40. Dong, T.; He, J.; Li, Z.-H.; Zhang, C.-P. ACS Sustainable Chem. Eng. 2018, 6, 1327-1335. doi:10.1021/acssuschemeng.7b03673

41. Tyrra, W.; Naumann, D.; Yagupolskii, Y. L. J. Fluorine Chem. 2003, 123, 183-187. doi:10.1016/s0022-1139(03)00118-0

42. Glenadel, Q.; Ghiazza, C.; Tlili, A.; Billard, T. Adv. Synth. Catal. 2017, 359, 3414-3420. doi:10.1002/adsc.201700904

43. Ghiazza, C.; Tlili, A.; Billard, T. Beilstein J. Org. Chem. 2017, 13 , 2626-2630. doi:10.3762/bjoc. 13.260

44. Ghiazza, C.; Debrauwer, V.; Billard, T.; Tlili, A. Chem. - Eur. J. 2018, 24, 97-100. doi:10.1002/chem.201705231

45. Ghiazza, C.; Khrouz, L.; Monnereau, C.; Billard, T.; Tlili, A. Chem. Commun. 2018, 54, 9909-9912. doi:10.1039/c8cc05256e

46. Ghiazza, C.; Debrauwer, V.; Monnereau, C.; Khrouz, L.; Médebielle, M.; Billard, T.; Tlili, A. Angew. Chem., Int. Ed. 2018, 57, 11781-11785. doi:10.1002/anie.201806165 Angew. Chem. 2018, 130, 11955-11959. doi:10.1002/ange.201806165

47. Ghiazza, C.; Monnereau, C.; Khrouz, L.; Médebielle, M.; Billard, T.; Tlili, A. Synlett 2019, 30, 777-782. doi:10.1055/s-0037-1610347

48. Ghiazza, C.; Kataria, A.; Tlili, A.; Toulgoat, F.; Billard, T. Asian J. Org. Chem. 2019, 8, 675-678. doi:10.1002/ajoc.201900027

49. Glenadel, Q.; Bordy, M.; Alazet, S.; Tlili, A.; Billard, T. Asian J. Org. Chem. 2016, 5, 428-433. doi:10.1002/ajoc.201600003

50. Glenadel, Q.; Tlili, A.; Billard, T. Eur. J. Org. Chem. 2016, 1955-1957. doi:10.1002/ejoc.201600197 


\section{License and Terms}

This is an Open Access article under the terms of the Creative Commons Attribution License (https://creativecommons.org/licenses/by/4.0). Please note that the reuse, redistribution and reproduction in particular requires that the author(s) and source are credited and that individual graphics may be subject to special legal provisions.

The license is subject to the Beilstein Journal of Organic Chemistry terms and conditions:

(https://www.beilstein-journals.org/bjoc/terms)

The definitive version of this article is the electronic one which can be found at:

https://doi.org/10.3762/bjoc.16.252 